Vol. 1, No. 1, 2020

https://doi.org/

P. Kosobutskyy, N. Nestor

Lviv Polytechnic National University

\title{
THE FORMULAS FOR SUM OF PRODUCTS OF SEQUENCES ASSOCIATED WITH THE METALLIC MEANS
}

(C) P. Kosobutskyy, N. Nestor 2020

In this paper, the regularities of convolution of sequences $\mathrm{c}$ of Fibonacci numbers $\left\{F_{n}\right\}$ generated by metallic means and the sum of products of two statistically independent sequences $\left\{F_{i}\right\}$ and $J_{n}=j \cdot \sin (0.5 \pi(n-j))$ are investigated. It is shown that the known closed forms of sums for convolution $\sum_{j=1}^{n} F_{i} F_{n-i}$ and product $\sum_{j=1}^{n-1} j F_{j} \cos \frac{(n-j-1) \pi}{2}$ are similar. Attention to the study of the convolution of two sequences of discrete data is associated with the use of this method for statistical signal processing. This problem involves calculating finite sums as discrete analogs of definite integrals. Such a problem is considered solved if the formula for the sum is expressed in a closed form as a function of its members and their number. equation

Key words: Golden ratio, metallic means, Fibonacci sequences, the roots of the quadratic

\section{Introduction}

Attention to the study of the convolution of two sequences of discrete data is associated with the use of this method for statistical signal processing [1-2]. This problem involves calculating finite sums as discrete analogs of definite integrals. Such a problem is considered solved if the formula for the sum is expressed in a closed form as a function of its members and their number. The convolution of two $F_{i} F_{n-i}$ recurrent Fibonacci-Luca sequences was studied in [3-5].

\section{Problem statement}

In this paper, the regularities of convolution of sequences $\mathrm{c}$ of Fibonacci numbers $\left\{F_{n}\right\}$ generated by metallic means [6] and the sum of products of two statistically independent sequences $\left\{F_{n}\right\}$ and $J_{n}=j \cdot \sin (0.5 \pi(n-j)) J_{n}=j \cdot \sin \frac{(n-j) \pi}{2}$ [7] are investigated. It is shown that the known closed forms of sums for convolution $\sum_{i=0}^{n} F_{i} F_{n-i}$ and product $\sum_{j=1}^{n-1} j F_{j} \cos \frac{(n-j-1) \pi}{2}$ are similar.

\section{Theoretical results}

Let be a two-dimensional system of Cartesian rectangular coordinates $p 0 q$ divided into four quadrants $p>0, q>0$ (first), $p>0, q<0$ (second), $p<0, q<0$ (third) i $p<0, q>0$ (fourth). In the third 
quadrant, there is a phase direction of points with coordinates $p \geq 1, q=-1$, which has the following positive solutions:

$$
\varphi_{p}=\frac{p+\sqrt{p^{2}+4}}{2}
$$

for the following quadratic equation

$$
\varphi_{p}^{2}-p \varphi_{p}-1=0
$$

known as the (quadratic) metallic means. So $\varphi_{p=2}=1+\sqrt{2}$ is known as the silver mean, $\phi_{p=3}=\frac{1}{2}(1+\sqrt{3})$ is called the bronze means.

Consider the decomposition of a square trinomial (2) in the form

$$
\varphi_{p}{ }^{n}=\alpha_{n} \varphi_{p}+\beta_{n}
$$

for positive roots $\phi_{p}( \pm p, q=-1)>0$ in second $\left(\varphi_{I I}\right)$ and the third $\left(\varphi_{I I I}\right)$ quadrants:

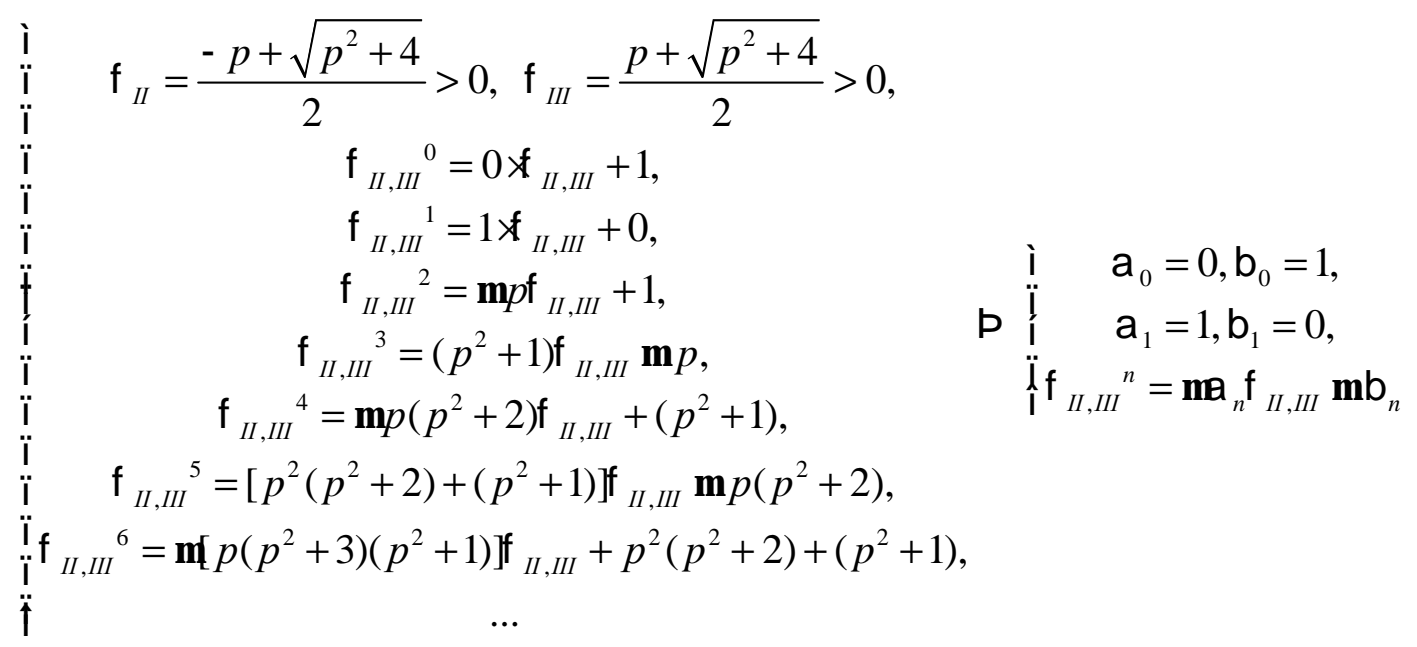

For the points $p= \pm 2, q=-1$ the sequences $\left\{\alpha_{n}\right\}$ have the following form:

$$
\left\{\begin{array}{rrrrrrcc}
n & 01 & 2 & 3 & 4 & 5 & 6 & 7 \\
\alpha_{n}, & 0,1, & \mathrm{~m} 2, & +5, & \mathrm{~m} 2, & +29, \mathrm{Mm} 70, & +169, \ldots \\
\beta_{n} & 1,0, & +1, & \mathrm{~m} 2, & +5, & \mathrm{~m} 2, & +29, & \mathrm{~m} 70,
\end{array}\right.
$$

\section{Discussion}

In the second quadrant, the sequence $\left\{\alpha_{n}=\alpha 2_{n}\right\}$ is alternating, it oscillates with the increasing amplitude around the equilibrium value $\alpha=0$ (Fig.1a). The Members of the sequence $\left\{\alpha_{n}\right\}$ are calculated by a recurrent formula

$$
\alpha_{n}=p \cdot \alpha_{n-1}+\alpha_{n-2}, \quad n \geq 2 .
$$

In the third quadrant, the sequence $\left\{\alpha_{n}=\alpha 3_{n}\right\}$ changes monotonically as the envelope of oscillations $\left\{\alpha_{n}=\alpha 2_{n}\right\}$ (Fig..1). The limit value for members of both neighboring sequences varies and goes to the root values (Fig.1)

$$
\lim _{n \rightarrow \infty} \frac{\alpha_{n}}{\alpha_{n-1}} \cong \mathrm{m} .414
$$


In general, $\frac{\alpha_{n}}{\alpha_{n-1}} \mathrm{i} \frac{\alpha_{n}}{\alpha_{n-2}}$ adjacent sequence values $\left\{\alpha_{n}\left(\alpha_{0}, \alpha_{1} ; p, q\right)\right\}$ in points $p, q$ along the first root lines are expressed employing chain fractions with the corresponding limits

$$
\left\{\begin{array}{l}
\frac{\alpha_{n}}{\alpha_{n-1}}=p+\frac{q}{\alpha_{n-1} / \alpha_{n-2}}=p+\frac{q}{p+\frac{q}{\alpha_{n-2} / \alpha_{n-3}}}=p+\frac{q}{p+\frac{q}{p+\frac{q}{\ldots}}} \\
\frac{\alpha_{n}}{\alpha_{n-2}}=q+\frac{p}{\alpha_{n-1} / \alpha_{n-2}}=q+\frac{p}{q+\frac{p}{\alpha_{n-2} / \alpha_{n-3}}}=q+\frac{p}{q+\frac{p}{q+\frac{p}{\ldots}}} \Rightarrow \lim _{n \rightarrow \infty} \frac{\alpha_{n}}{\alpha_{n-1}}=\max \left(x_{ \pm}\right),
\end{array}\right.
$$

oscillating or changing monotonically in the second quadrant under arbitrary initial conditions. The sequence $\left\{\alpha_{n}=\alpha 3_{n}\right\}$ refers to the classical Fibonacci sequence

$$
F_{n}=p F_{n-1}+F_{n-2}, n \geq 2, F_{0}=0, F_{1}=1, p=2, q=1 .
$$

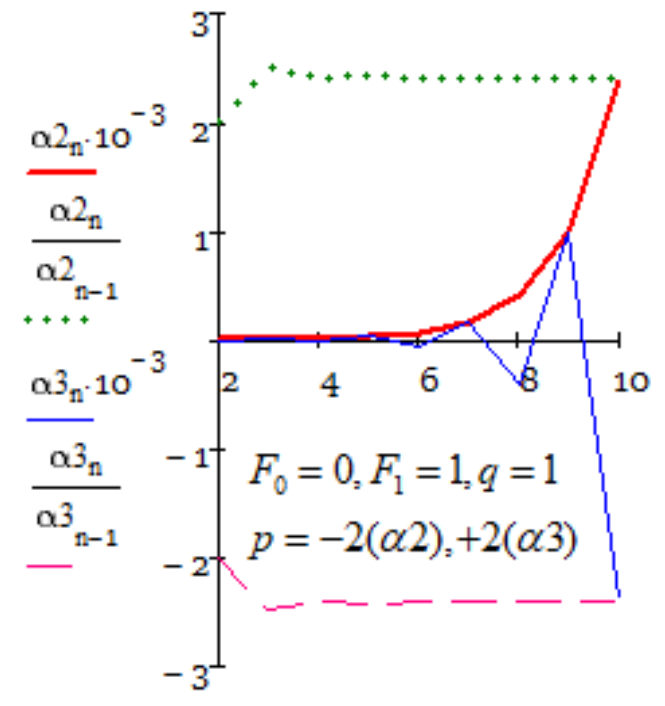

Fig. 1 Dynamics of changes in the recurrent sequence (9) and the relations of its neighboring members

Consider the convolution of two sequences (9) generated in the second $\left(\alpha_{n}{ }^{*} \alpha_{n}\right)$ and the third $\left(F_{n} * F_{n}\right)$ quadrants, which are calculated as the sums $\sum_{i=0}^{n} \alpha_{i} \cdot \alpha_{n-i}$ (table 1) and $\sum_{i=0}^{n} F_{i} \cdot F_{n-i}$ (table 2 ) products of statistically dependent multipliers by the algorithm [9]. As follows from tables 1 i 2 , the convolutions differ only in the sign of the summation result.

The Regularities of products $\alpha_{i} \cdot \alpha_{n-i}, \frac{\alpha_{i}}{\alpha_{i+1}} \cdot \frac{\alpha_{n-i}}{\alpha_{n-i+1}}$ and $F_{i} \cdot F_{n-i}, \frac{F_{i}}{F_{i+1}} \cdot \frac{F_{n-i}}{F_{n-i+1}}$ are similar to each other, taking into account the sign. The Regularities of the formation of sums $\sum_{i=0}^{n} \alpha_{i} \cdot \alpha_{n-i}$ and $\sum_{i=0}^{n} F_{i} \cdot F_{n-i}$ statistically dependent multipliers of products are shown in Figure 2. 
Table 1

Convolution the two sequences $\left\{\alpha_{n}\right\}$ for $n=7$

\begin{tabular}{|c|c|c|c|c|c|c|c|c|c|}
\hline $\mathrm{j}$ & $\mathbf{0}$ & $\mathbf{1}$ & $\mathbf{2}$ & $\mathbf{3}$ & $\mathbf{4}$ & $\mathbf{5}$ & $\mathbf{6}$ & $\mathbf{7}$ & Sum \\
\hline$\alpha_{i}$ & 0 & 1 & -2 & 5 & -12 & 29 & -70 & 169 & \\
\hline$\alpha_{7-i}$ & 169 & -70 & 29 & -12 & 5 & -2 & 1 & 0 & \\
\hline$\sum_{i=0}^{n} \alpha_{i} \cdot \alpha_{n-i}$ & 0 & -70 & -58 & -60 & -60 & -58 & -70 & 0 & -376 \\
\hline
\end{tabular}

Table 2

Convolution the two sequences $\left\{F_{n}\right\}$ for $\mathbf{n}=7$

\begin{tabular}{|c|c|c|c|c|c|c|c|c|c|}
\hline $\mathrm{j}$ & $\mathbf{0}$ & $\mathbf{1}$ & $\mathbf{2}$ & $\mathbf{3}$ & $\mathbf{4}$ & $\mathbf{5}$ & $\mathbf{6}$ & $\mathbf{7}$ & Sum \\
\hline$F_{i}$ & 0 & 1 & 2 & 5 & 12 & 29 & 70 & 169 & \\
\hline$F_{7-i}$ & 169 & 70 & 29 & 12 & 5 & 2 & 1 & 0 & \\
\hline$\sum_{i=0}^{n} F_{i} \cdot F_{n-i}$ & 0 & 70 & 58 & 60 & 60 & 58 & 70 & 0 & 376 \\
\hline
\end{tabular}

For the recurrent sequences (9), a closed-form of the sum $\sum_{i=0}^{n} F_{i} F_{n-i}$ with arbitrary values of the coefficients $p, q$ was first found in [7].

$$
\sum_{i=0}^{n} F_{i} F_{n-i}=\frac{(n-1) p F_{n}+2 n q F_{n-1}}{p^{2}+4 q}=\frac{(n-1) p F_{n}+2 n F_{n-1}}{p^{2}+4}=\Sigma(n, p, q, F) .
$$

For $p=1, q=1$ and $F_{0}=0, F_{1}=1$ formula (13) has the form

$$
\sum_{i=1}^{n} F_{i} F_{n-i}=\frac{n L_{n+1}+2 F_{n-1}}{5} .
$$

As can be seen from Fig. 2, the formula for the sum in closed form (10) for the sequence $\left\{\alpha_{n}\right\}$ does not come true but comes true only at the vertices of oscillations.

The following formula was found for the sum [7]

$$
\sum_{j=1}^{n-1} F_{j} \cdot F_{n-j}=\sum_{j=1}^{n-1} F_{j} \cdot J_{j}=\sum_{j=0}^{n} F_{j} \cdot j \cdot \cos \frac{(n-j-1) \pi}{2} .
$$

In the formula (12), a multipliers $F_{j}$ i $J_{j}$ are statistically independent, so the sum $\sum_{j=1}^{n-1} F_{j} \cdot J_{j}$ is valid only for the sequence $\left\{F_{n}\right\}$ (Fig.2). Finally, we present other formulations of the formula (12) :

$$
\sum_{i=0}^{n} F_{i} F_{n-i}=\sum_{j=0}^{n} F_{j} \cdot(n-j) \sin \frac{j \pi}{2}=\sum_{j=0}^{n} F_{n-j} \cdot j \sin \frac{(n-j) \pi}{2} .
$$




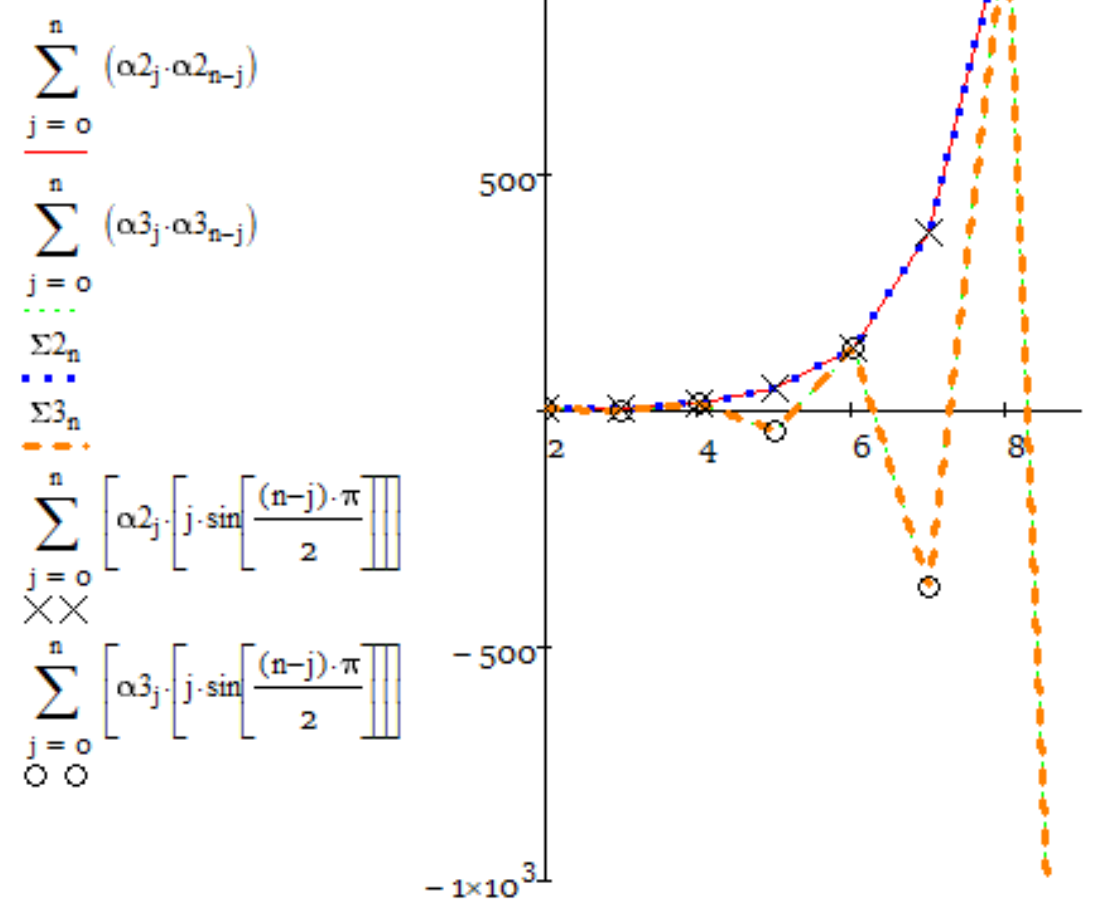

Fig. 2. Comparative analysis of convolution of the sequence terms and (12)-(13)

We formulate the next two propositions:

Proposition 1. $\quad \sum_{i=0}^{n} F_{i} F_{n-i}=\sum_{j=0}^{n} F_{j} \cdot(n-j) \sin \frac{j \pi}{2}=\sum_{j=0}^{n} F_{n-j} \cdot j \sin \frac{(n-j) \pi}{2}$

Proposition 2.

$$
\sum_{i=0}^{n}(n-j) F_{n-j} \cos \frac{(j-1) \pi}{2}=n \sum_{i=0}^{n} F_{n-j} \cos \frac{(j-1) \pi}{2}-\sum_{i=0}^{n} j F_{n-j} \cos \frac{(j-1) \pi}{2}=
$$

$$
=n \sum_{i=0}^{n} F_{n-j} \sin j \frac{\pi}{2}-\sum_{i=0}^{n} j F_{n-j} \sin j \frac{\pi}{2}
$$

Since for initial condition $F_{0}=0, F_{1}=1$ satisfy equal -

$$
\sum_{i=0}^{n}(n-j) F_{n-j} \sin j \frac{\pi}{2}=\sum_{i=0}^{n} j F_{j} \sin j \frac{\pi}{2},
$$

then

$$
\sum_{i=0}^{n}(n-j) F_{n-j} \sin j \frac{\pi}{2}=\sum_{i=0}^{n} j F_{j} \cos \frac{(n-j-1) \pi}{2}=\sum_{i=0}^{n} j F_{j} \sin j \frac{\pi}{2}
$$

\section{Conclusion and future work}

In this paper, the regularities of convolution of sequences $\mathrm{c}$ of Fibonacci numbers $\left\{F_{n}\right\}$ generated by metallic means and the sum of products of two statistically independent sequences $\left\{F_{i}\right\}$ and $J_{n}=j \cdot \sin (0.5 \pi(n-j))$ are investigated. It is shown that the known closed forms of sums for convolution $\sum_{i=0}^{n} F_{i} F_{n-i}$ and product $\sum_{j=1}^{n-1} j F_{j} \cos \frac{(n-j-1) \pi}{2}$ are similar. 
To further our developing we are planning to expand the idea of using explored parameters in the algorithm of modeling systems with the different parameters

1. J.Proakis, D.Manolakis. Digital Signal Processing. Principles, by Prentice-Hall, Inc. Simon \& Schuster/A Viacom Company Upper Saddle River, New Jersey,1996, Algorithm, and Applications.WEB-resource: https://engineering.purdue.edu/ ee538/DSP_Text_3rdEdition.pdf.

2.T.Kim, D.Dolgy, D.Kim, et.al. Convolved Fibonacci numbers and their applications. ARS Combinatoria, 135 (2017 ): 228; arXiv:1607.06380 [math.NT] (or arXiv:1607.06380v1 [math.NT] for this version)

3.T. Szakács: Convolution of second-order linear recursive sequences I.. Annales Mathematicae et Informaticae 46 (2016) 205-216.

4. Z. Chen, L. Qi . Some Convolution Formulae Related to the Second-Order Linear Recurrence Sequence Symmetry (2019), 11, 788-798.

5.P. Moree. Convoluted Convolved Fibonacci Numbers. Journal of Integer Sequences, Vol. 7 (2004).

6. Vera W. De Spinadel. The Family of Metallic Means. (2014), http://www.mi.sanu.ac.rs/vismath/spinadel/].

7. W. Zhang: Some Identities Involving the Fibonacci Numbers. The Fibonacci Quarterly 35 (3) (1997) 225229.

8. T. Komatsu, Z. Masáková, E. Pelantová. Higher-order identities for Fibonacci numbers, Fibonacci Quart. 52 (2014), 150-163.

9. J. W. Pierre. A novel method for calculating the convolution sum of two finite-length sequences. IEEE Transactions on Education, vol. 39, issue 1 (1996), 77-80.

П. Кособуцький, Н. Нестор Національний університет "Львівська політехніка"

ФОРМУЛИ СУМ ДОБУТКІВ ПОСЛІДОВНОСТЕЙ, ЗВ'ЯЗАНИХ З МЕТАЛІЧНИМИ СЕРЕДНІМИ

(C) Кособуиьький П., Нестор Н., 2020

У цій роботі досліджуються закономірності згортки послідовностей сум чисел Фібоначчі $\left\{F_{n}\right\}$, породжених металевими середніми, та суми добутків двох статистично незалежних послідовностей $\left\{F_{n}\right\}$ та $J_{n}=j \cdot \sin (0.5 \pi(n-j))$. Показано, що відомі закриті форми сум для згортки $\sum_{j=1}^{n} F_{i} F_{n-i}$ та добутків $\sum_{j=1}^{n-1} j F_{j} \cos \frac{(n-j-1) \pi}{2}$ с подібними. Така увага до вивчення згортки двох послідовностей дискретних даних пов'язана із застосуванням цього методу для статистичної обробки сигналів. Ця задача передбачає обчислення скінченних сум як дискретних аналогів певних інтегралів. Така проблема вважається вирішеною, якшо формула суми виражається у закритому вигляді як функція її членів та їх кількості.

Ключові слова: Золоте січення, металеві середні, послідовності Фібоначчі, корені квадратного рівняння 